\title{
条件基因打靶研究存在的主要问题及对策
}

林福玉，杨晓

军事医学科学院生物工程研究所发育和疾病遗传学研究室, 蛋白质组学国家重点实验室, 北京 100071

摘要: 基于 Cre-loxP 等位点特异性重组系统的条件基因打靶技术在解析基因功能和制备疾病小鼠模型方面发 挥着极其重要的作用。但包括 Cre 重组酶转基因的表达模式不理想、重组效率存在差异、Cre 重组酶的毒性等 在内的 Cre-loxP 重组系统相关的缺陷以及条件基因打靶技术本身存在的问题, 如遗传背景、育种策略、实验对 照、基因代偿等方面的影响往往被忽略, 严重影响基因功能和小鼠表型解析的准确性。针对这些问题, 精细调 控实现 Cre 重组酶的理想时空特异性表达、详尽地分析 Cre 重组酶的重组效率、降低 Cre 重组酶的毒性、遗传 背景单一化、优化育种策略、设立严格实验对照、多基因联合条件基因打靶等诸多解决方案应予以采纳。

关键词：条件基因打靶; Cre-loxP; 位点特异性重组; 遗传背景

\section{Issues and solutions of conditional gene targeting}

\author{
LIN Fu-Yu, YANG Xiao
}

Genetic Laboratory of Development and Diseases, State Key Laboratory of Proteomics, Institute of Biotechnology, Beijing 100071, China

\begin{abstract}
Conditional gene targeting, based on the site-specific recombination system such as Cre-loxP, plays a vital role in the study of gene functions and the generation of disease mouse models. It was always under consideration that there were problems in the Cre-loxP recombination system, such as illegal expression pattern of Cre transgene, variation of Cre recombination efficiency and toxicity of Cre recombinase, as well as the potential influences of genetic background, breeding strategy, experimental control and gene compensation. Oversights of these issues may have a profound influence on the accuracy of gene functional dissection and conditional gene targeting mice phenotypic interpretation. Accordingly, solutions should be adopted including delicate regulative control of temporal-spatial specific Cre expression, detailed detection of Cre recombination efficiency, reduction of Cre toxicity, simplification of mouse genetic background, optimization of breeding, setting up of proper control and combined conditional gene targeting.
\end{abstract}

Keywords: conditional gene targeting; Cre-LoxP; site-specific recombination; genetic background

条件基因打靶是基于位点特异性重组酶 Cre/FLP重组酶切除或者颠倒1oxP/FRT针定的DNA 片段, 在小鼠体内以一种组织/细胞特异性或者可诱 导等“有条件性的” 方式引入突变, 从而研究基因
功能的强有力的技术。来源于细菌噬菌体的Cre重组 酶及其特异识别序列loxP位点构成条件基因打靶常 用的系统 ${ }^{[1 \sim 3]}$ 。Cre-loxP系统包含两类小鼠，一类基 因针定floxed小鼠是在各种目的基因的两侧通过同

收稿日期: 2010-10-28; 修回日期: 2011-03-15

基金项目: 蛋白质组学国家重点实验室深入研究课题(编号：SKLP-K200902), 国家科技重大专项新药创制(编号：2009ZX09501-027)资助 作者简介: 林福玉, 博士, 副研究员, 研究方向 : 转基因动物。Tel: 010-66948849; E-mail: linfuyu2000@yahoo.com.cn

通讯作者:杨晓, 博士, 研究员, 研究方向 : 分子遗传学。E-mail: yangx@nic.bmi.ac.cn 
源重组引入 34 个碱基对的loxP位点的小鼠，另一类 $C r e$ 重组酶转基因小鼠是各种组织/细胞特异性或者 可诱导的方式调控下表达Cre重组酶的小鼠。通过上 述两类不同小鼠组合交配，特异条件调控表达的Cre 重组酶将介导loxP位点间基因片段的重组, 获得多 种条件基因打靶小鼠。常规完全敲除那些小鼠胚胎 发育必需的重要基因时, 往往导致小鼠胚胎期死亡 而难以分析基因在成体中功能。条件基因打靶可以 克服完全基因打靶这一缺点, 能够用于更加精细地 解析基因在特定组织、特定发育阶段的功能。条件 基因打靶除用于基因功能基础研究之外，发明 10 多 年以来在生物医学研究领域中已日渐广泛, 还成功 用于构建“第二代” 人类疾病小鼠模型, 可以更好 地模拟人类疾病相关体细胞突变。正是由于条件基 因打靶的广泛应用，此实验技术体系内在固有的一 些问题, 如 $C r e$ 重组酶转基因的表达模式、靶基因重 组效率的差异、Cre重组酶的毒性、遗传背景、育种 策略、实验对照、基因圥余等诸多方面越来越引起 人们的强烈关注 ${ }^{[4,5]}$, 如果忽略这些问题, 很容易导 致错误的实验结论。

1 Cre 重组酶表达的保真性和重组效率的 不同

\subsection{Cre 重组酶表达的保真性}

利用条件基因打靶技术可以在特定的细胞类型 或者组织器官(空间特异性)实现对小鼠基因组的遗 传改造, 也可以在小鼠生命周期的特定发育阶段(时 间特异性)在特定的细胞或者组织中进行遗传修饰。 这种调控的基础是 $C r e$ 重组酶转基因表达的保真性。 这里的“保真性”是指 Cre 重组酶在小鼠中的表达模 式(包括 Cre 重组酶表达的强度、空间分布和发育阶 段等)与研究人员所预期的表达模式一致。实现 Cre 重组酶特异性时空调控表达的策略多种多样: 可以 将特异的启动子和增强子与 $\mathrm{Cre}$ 基因相连形成经典 的 Cre 转基因载体，通过显微注射引入小鼠基因组; 可以将 Cre 的 cDNA 基因通过“基因敲入”整合到小 鼠基因组合适的基因调控序列附近; 也可以整合上 述两种方法, 将包含细胞/组织特异性表达或者特定 发育阶段表达的基因组序列的细菌人工染色体改造 成表达 Cre 的转基因表达载体。
虽然研究人员尽力将组织/时间特异的基因表 达调控序列与 Cre 编码区组合并将这种表达框架引 入基因组中, 但还不能完全保证 Cre 重组酶转基因 按照预期表达。通过小鼠受精卵显微注射获得的 Cre 重组酶转基因小鼠, 由于转基因随机整合位点染色 体结构的不同形成的“位点效应”，导致不同的转基 因品系之间 Cre 重组酶的表达模式可能不同。Cre 重组酶基因敲入小鼠 Cre 重组酶的表达受整合位点 内源性的转录调控, 其表达模式理论上应该与整合 位点内源基因的表达模式一致，但如果内源基因位 点表达水平不高, 重组酶的表达水平能否实现体内 重组完成打靶过程就需要谨慎的检测评价。

\subsection{Cre 重组酶的重组活性及作用原理}

即使利用相同的 $\mathrm{Cre}$ 重组酶转基因小鼠，不同 靶基因的重组效率也千差万别，因为不同loxP针定 的靶基因对 Cre重组酶介导重组反应的敏感性差异 明显 ${ }^{[6]}$ 。有些染色体区的基因似乎对 $\mathrm{Cre}$ 重组反应具 有抵抗性。极端情况下，同一种Cre重组酶转基因小 鼠能够成功剔除一种针定基因, 而对另外一种针定基 因却完全没有作用。B细胞特异的CD19-Cre转基因实 验 ${ }^{[7]}$ 提供了很好的例证: CD19-Cre能够有效介导成熟B 细胞中大多数 loxP针定基因的剔除, 非成熟 $\mathrm{B}$ 细胞和 前 $\mathrm{B}$ 细胞中部分基因的剔除，而几乎不能介导 $\mathrm{B}$ 祖细胞 中基因的剔除。其内在的机理目前尚不清楚, 原因可 能是不同针定基因的loxP位点由于处于不同的染色质 结构差异造成与Cre重组酶的结合能力不同。

位点特异性重组的机制是两个重组靶位点/loxP 位点之间的随机碰撞。对于 $M$ 期包埋在染色体内的 基因而言，随机碰撞的几率受两个因素的影响：第 一个因素是两个位点在染色体上的距离。两个位点 相距越远, 相互碰撞的概率越小, 导致重组发生的 几率越低。这是可以确定的; 第二个因素是未知的, 即 loxP 在基因中放置的位置不同造就的“位置效应”, 导致条件基因打靶过程中的不可控性。针定靶基因 时一般将两个 loxP 放置在一个基因的关键区段的外 显子或者重组后将导致移码突变的外显子的两侧。 当然最好将整个靶基因全部针定, 但针定片段太长 往往影响打靶效率。因此在设计条件基因打靶时, 仔细研究基因的结构、寻求锚定区域的长短与基因 的外显子之间的平衡对于打靶效率有重要影响。 


\section{3 条件基因打靶系统 Cre 活性分析与检测}

常规组织特异性启动子调控的 Cre 转基因小鼠 的 Cre 表达依赖于转基因整合位点。通常的应对做 法是构建几个表达 Cre 的转基因小鼠系, 然后评估 Cre 的表达部位和水平，鉴定出最有效的鼠系用于 和基因针定小鼠交配实现条件基因打靶。目前多应 用报告小鼠来分析 Cre 重组酶表达的保真性。这类 报告小鼠的等位基因通常是标记基因，如绿色苂光
蛋白 $(G F P)$ 或者 $\beta$-半乳糖苷酶 $(\beta-G a l)$ 基因, 标记基 因的前面有loxP针定的“停止(STOP)”序列，Cre重 组酶介导的重组发生前标记基因表达被阻止，只有 在特异调控下的Cre表达后，介导针定的STOP表达 框在特定的组织/器官、发育阶段重组切除后, 标记 基因才能表达。报告小鼠成为检测活体内Cre重组酶 活性和作用的重要遗传学工具小鼠。至今已经有很 多Cre和Flp报告小鼠(表 1$)^{[2]}$ 。

表 1 Cre 和 Flp 报告小鼠

\begin{tabular}{|c|c|c|c|c|c|c|}
\hline 报告小鼠 & 重组酶 & 启动子/增强子 & 转基因 $\mathrm{T} /$ 敲入 $\mathrm{KI}$ & 报告基因 & 报告基因条件表达方式 & 参考文献 \\
\hline R26R & Cre & ROSA26 & KI & $\beta-G a l$ & ELC & [8] \\
\hline cAct-XstopXlacZ & Cre & 鸡 $\beta$-肌动蛋白 & $\mathrm{T}$ & 核内 $\beta-G a l$ & ELC & [9] \\
\hline floxLacZ & Cre & 鸡 $\beta$-肌动蛋白 & $\mathrm{T}$ & $\beta$-Gal & ELC & [10] \\
\hline$c \beta$-STOP-lacZ & Cre & 鸡 $\beta$-肌动蛋白 & $\mathrm{T}$ & 核内 $\beta-G a l$ & ELC & [11] \\
\hline ROSA $26^{\text {flox }}$ & Cre & ROSA26 原病毒 & KI & $\beta-G a l$ & ELC & [12] \\
\hline $\mathrm{Z} / \mathrm{AP}$ & Cre & $C A G$ & $\mathrm{~T}$ & $\begin{array}{l}\beta-G a l \\
P L A P\end{array}$ & $\overline{-}$ & [13] \\
\hline UCR & Cre & $G 3 B P(B T 5)$ & KI & $\beta-G a l$ & ELC & {$[14]$} \\
\hline $\mathrm{Z} / \mathrm{EG}$ & Cre & $C A G$ & $\mathrm{~T}$ & $\begin{array}{l}\beta-G a l \\
e G F P\end{array}$ & $\begin{array}{l}- \\
\text { ELC }\end{array}$ & [15] \\
\hline CAG-CAT-EGFP & Cre & $C A G$ & $\mathrm{~T}$ & $e G F P$ & ELC & [16] \\
\hline ROSA26-EGFP $^{\mathrm{f}}$ & Cre & ROSA26 & KI & $e G F P$ & ELC & [17] \\
\hline LSLMAP2GFP & Cre & 鸡 $\beta$-肌动蛋白 & $\mathrm{T}$ & $M A P 2-G F P$ & ELC & [18] \\
\hline ZW (CAG-lacZ-WGA) & Cre & $C A G$ & $\mathrm{~T}$ & $\begin{array}{l}\beta \text {-Gal } \\
W G A\end{array}$ & $\overline{-}$ & [19] \\
\hline $\begin{array}{l}\text { Z/RED } \\
\text { (CAG-Bgeo,-DsRed*MST) }\end{array}$ & Cre & $C A G$ & $\mathrm{~T}$ & $\begin{array}{l}\beta-G a l \\
R F P\end{array}$ & $\overline{-}$ & [20] \\
\hline CAG-tdTomato & Cre & $C A G$ & KI & RFP variant & ELC & {$[21]$} \\
\hline piGAP & Cre & $C A G$ & $\mathrm{~T}$ & $\begin{array}{l}e G F P(F) \\
h P L A P\end{array}$ & $\overline{-}$ & [22] \\
\hline R26R-TRPV1-ECFP & Cre & ROSA26 & KI & $\begin{array}{l}\operatorname{TrpV1} \\
\text { ECFP }\end{array}$ & $-\overline{E L C}$ & [23] \\
\hline ZW (CAG-lacZ-WGA) & Cre & $C A G$ & $\mathrm{~T}$ & $\begin{array}{l}\beta-G a l \\
W G A\end{array}$ & $\overline{-}$ & [24] \\
\hline luc-gal(Tg) & Cre & $C A G$ & $\mathrm{~T}$ & $\begin{array}{l}E G F P \\
L u c / \beta-G a l\end{array}$ & $\overline{-}$ & [25] \\
\hline Hmgcr::FRTZ & FLP & $H m g c r$ 序列 & $\mathrm{T}$ & 核内 $\beta-G a l$ & $\mathrm{EFC}$ & [26] \\
\hline R26::FRAP & FLP & ROSA26 & KI & $h P L A P$ & $\mathrm{EFC}$ & [27] \\
\hline R26FR & FLP & ROSA26 & $\mathrm{KI}$ & $\beta-G a l$ & $\mathrm{EFC}$ & [28] \\
\hline R26::FLAP & $\mathrm{FLP}+\mathrm{Cre}$ & ROSA26 & KI & $\begin{array}{l}e G F P(F) \\
h P L A P\end{array}$ & $\begin{array}{l}\mathrm{EFC} \\
\mathrm{EFC}+\mathrm{ELC}\end{array}$ & [29] \\
\hline R26: NZG & $\begin{array}{l}\text { Cre } \\
\text { FLP }\end{array}$ & $C A G$ & KI & $\begin{array}{l}\beta-G a l \\
E G F P\end{array}$ & $\begin{array}{l}- \\
\text { ELC }\end{array}$ & {$[30]$} \\
\hline Thy1-Brainbow1.0/1.1/2.1 & $\begin{array}{l}\text { Cre } \\
\text { (FLP) }\end{array}$ & Thyl & $\mathrm{T}$ & $\begin{array}{l}R F P \\
C F P / E Y F P /(G F P \\
\text { in 2.1) }\end{array}$ & $\overline{-}$ & [31] \\
\hline R26R-EYFP & Cre & ROSA26 & KI & $e Y F P$ & ELC & [32] \\
\hline R26R-ECFP & Cre & ROSA26 & KI & $e C F P$ & ELC & {$[32]$} \\
\hline
\end{tabular}

CAG: 鸡 $\beta$-肌动蛋白启动子偶联巨细胞病毒增强子; Hmgcr 羟甲基戊二酰辅酶 $\mathrm{A}$ 还原酶; $\beta$-gal: $\beta$-半乳糖苷酶; ELC: LoxP 锚定的 STOP 表达框 的切除; hPLAP 人胎盘碱性磷酸酶; UCR, 通用型条件 lacZ 报告小鼠; EYFP, 增强型黄色苂光蛋白; ECFP, 增强型蓝绿色苂光蛋白; EFC: FRT 针定的 STOP 表达框的切除; eGFP(F)：增强型绿色苂光蛋白-法尼氏酰化(farnistylated); 虚线表示重组前报告蛋白持续表达; WGA：小麦胚 凝集素(植物凝集素); Thy 1：胸腺细胞抗原 1; Trpv1：瞬时受体电位阳离子通道 V 亚家族成员 1; Luc: 苂光素酶。 
目前应用最为广泛的报告小鼠是R26R小鼠 ${ }^{[8]}$ 。 随着研究的不断需要和深入, 这类报告小鼠的种类 还在不断增加。最近一种称为“脑虹”的报告基因小 鼠 ${ }^{[31]}$ 的复杂和精细显示了研究人员的巨大智慧, 他 们用几种LoxP位点针定 2 到 3 种荧光蛋白, 使小鼠 的脑组织在Cre重组酶的作用下呈现彩虹样结构, 可 检测到神经细胞会表达多达 166 种可分辨的不同苂 光, 为神经系统的研究提供了有利的工具。

应用报告小鼠的前提是它们能够真实的反映靶 基因的剔除状态，但不同基因对 $\mathrm{Cre}$ 重组酶介导的重 组反应敏感性的不同 ${ }^{[6]}$ 会限制这种分析。尽管标记 基因这种方法可以在单细胞水平上检测 $\mathrm{Cre}$ 重组酶 的特异活性，但“真正的”条件基因打靶实验中这种 特异的活性并不一定完全相同。一种表达黄色菼光 蛋白的报告小鼠 ${ }^{[32]}$ 经 Cre 重组酶重组表明 $\mathrm{c}-\mathrm{Kit}^{+}$原 B 细胞中重组率为 $5 \%$, 前B细胞中为 $40 \%$ 。然而, 转 录因子 $M c l-l^{[34]}$ 和 $c-M y b^{[35]}$ 条件打靶小鼠 $\mathrm{B}$ 细胞发育 严重阻滞在原B细胞向前B细胞转换阶段, PCR 分析 表明, 两种实验中在这一阶段的绝大部分细胞中两 种基因都发生了重组 ${ }^{[34,35]}$ 。因此, 报告小鼠得到的 结果只能作为一种参考, 这依赖于报告小鼠中 loxP 针定的“停止”表达框的基因位点对Cre重组酶的敏 感性和真正实验中 loxP针定的靶基因对 Cre 重组酶 的敏感性是否完全一致。同时机体所有细胞中报告 基因的表达原则上都能被检测到。在某种特定类型 的细胞中报告基因不表达，并不能证明Cre重组酶没 有表达或在其他的基因位点没有重组活性。为鉴定 Cre转基因小鼠介导重组的的效率及特异性, 可以 用多种不同的报告小鼠来检测，同时检测结果可以 反映出 $\mathrm{Cre}$ 重组酶针对不同基因的打靶效率可能会 有所不同。

为确保条件打靶实验中的特异性, 最好对小鼠 的不同组织 Cre 重组酶的表达模式和 loxP 针定的靶 基因进行全面分析, 同时必须检测 Cre 重组酶介导 重组前后基因组发生的变化。检测 Cre 重组酶小鼠 在不同组织中介导的重组的最直接的方法是应用 Southern 杂交来区分野生型等位基因、 loxP 针定等 位基因和重组后的等位基因, 但这种方法灵敏度有 限, 而且需要大量的细胞。细胞数量较少时可以选 择 PCR 方法检测。

在靶基因条件打靶后, 从细胞水平上追踪以及
区分突变型和野生型细胞的另一种方法就是利用原 位杂交或免疫组化染色来检测野生型细胞中的 mRNA 和蛋白, 但这种检测在很大程度上依赖于探 针和抗体的灵敏性及特异性。事实上, 如果靶基因 只有一小部分编码区被剔除, 那么能够检测 mRNA 的表达被剔除的原位杂交探针可选择的长度不大， 其特异性可能较差, 不能有效区分突变型和野生型 细胞。因此，条件打靶时剔除基因的一大段编码区 有利于寻找良好的原位杂交探针。在没有靶基因编 码蛋白的抗体无法进行免疫组化实验时这显得更为 重要。

另外一种更直接的检测方法是在条件打靶的靶 基因后插入一个报告基因(如 $l a c Z$ 、碱性磷酸酶、 $e G F P$ 等), 报告基因(通常在 $5^{\prime}$ 端有一个剪接受体 $\mathrm{SA}$ ) 一般放置在最 3'端的重组酶识别位点的后面, 包含 报告基因的中靶等位基因在重组酶介导的切除后, 靶基因以一种组织特异性方式被剔除，同时报告基 因被激活并对发生重组的细胞进行标记 ${ }^{[36,37]}$, 这样 可以直接观测到感兴趣的组织或细胞中靶基因的剔 除效率，有助于解析打靶小鼠表型。这种方法的前 提条件是靶基因的启动子足够强，报告基因能够在 特定细胞或者所有细胞中被激活表达并能被检测 到。从此意义上来说, 这种检测虽可以提高灵敏度, 但不像Southern杂交那么直接。

\subsection{Cre 重组酶不“保真” 造成的额外优点}

值得欣慰的是, Cre转基因小鼠的不保真性可能 会拓展小鼠的应用空间。B细胞从不成熟的过渡细胞 分化成存活较长的卵泡和边缘区B细胞时, CD21 被 诱导表达, 因此CD21-Cre3A转基因小鼠最初被设计 用于成熟 $\mathrm{B}$ 细胞特异的基因功能的遗传学分析。应用 $C D 21-C r e 3 A$ 细菌人工染色体转基因小鼠介导loxP针 定的转录因子 $y y 1$ 等位基因的条件基因打靶 CD21-Cre 3A; yy $1^{\text {floxedfloxed }}$ 小鼠实验 ${ }^{[38]}$ 就呈现出 Cre 表达的不保真性: CD21-Cre3A的确能介导脾脏成熟 B细胞内loxP针定基因的重组 ${ }^{[38]}$ ，也能介导同样表 达CD21 的卵泡枝状细胞内针定基因的重组 ${ }^{[39]}$, 但 其他不同的组织中也会发生重组剔除, 最明显的是 前脑。实际上, CD21-Cre 3A, yy $1^{\text {floxed floxed }}$ 条件基因打 靶纯合子小鼠很早死亡, 表现出众多发育异常, 其 中前脑几乎完全缺失 ${ }^{[4]}$ 。此结果暗示即使 $C r e$ 敲入在 
成熟B细胞和卵泡枝状细胞中表达 $C D 21$ 位 点 ${ }^{[40]}$ 也不一定能保证 Cre 转基因表达的保真性, 但 CD21-Cre 3A 小鼠出人意料地成为一种还可用于前 脑条件基因打靶的工具小鼠。这种由于基因的表达 调控和表达模式尚不清楚就应用其调控序列制备的 $C r e$ 转基因小鼠出现易位表达的例子很多，拓宽了 不保真 $C r e$ 转基因小鼠的条件打靶应用范围。

\section{2 条件基因打靶中的嵌合体}

在条件基因打靶中稳定表达 Cre 重组酶的转基 因小鼠品系至关重要。但大部分组织或细胞特异性 Cre 转基因小鼠并不是 $100 \%$ 有效的，当这种 Cre 转 基因小鼠与 floxed 小鼠交配时，特定组织只有部分 细胞由于基因剔除失去功能, 这样就产生嵌合体(个 体中特定组织内的细胞的基因型不完全相同)。残余 存在的野生型细胞可能会掩盖打靶小鼠应有的表型, 也有可能产生完全不同的表型, 会加大小鼠表型分 析的难度。当靶基因以非细胞自主性方式起作用, 特别是当靶基因编码分泌型信号分子时, 仅有的一 小部分野生型细胞表达基因产物可能会完全挽救突 变的表型。相反, 受体或细胞内信号转导分子等细 胞自主性蛋白基因的条件打靶, 并不总是需要达到 $100 \%$ 的重组效率就可以产生表型，尽管可能与完全 基因打靶不完全相同。

Cre 重组酶介导的条件打靶是个动态过程, 也 造成所有的靶组织/细胞中同时发生重组。发生重组 的细胞数目开始可能处于很低的水平, 随着时间形 成乙状曲线，最终才达 $100 \%$ 饱和。Cre 重组酶的表 达特性和 LoxP 针定序列的特点影响该曲线。Cre 重 组酶介导的条件打靶小鼠的靶细胞中靶蛋白的缺失 时间存在延迟，这种延迟具有几个层面：首先是 Cre 转录开始, 随后是 Cre 蛋白的翻译和聚集, 然后 Cre 催化 loxP 针定的靶基因的重组。这个过程会剔除靶 蛋白的转录模板, 但重组前的靶基因转录的 mRNA 依然会在一定阶段内在细胞内作为模板翻译成蛋白 质。翻译过程完成后, 靶蛋白还需要在靶细胞内降 解。RNA 和蛋白质在细胞内的半衰期差异巨大, 如 果基因产物越稳定，也就意味着从基因剔除到出现 表型的时间间隔越长; 同时 RNA 和蛋白质能在很宽 的浓度范围内保持在细胞内发挥正常的功能。这种 问题的存在最初可能会掩盖基因灭活的表型。由于
Cre 和靶基因表达的动力学和靶蛋白及其 mRNA 的 稳定性，这种延迟会达几小时甚至数天，限制了条 件打靶在快速发育过程中基因的功能研究。因此, 在应用条件基因打靶研究基因功能之前，应该对目 的基因的性质有所考虑。总体来讲，有必要分析条 件基因打靶 Cre 介导的重组后细胞内靶基因的 RNA 或蛋白质剔除的情况。

正是由于组织或细胞特异性条件基因打靶的不 完全性, 提供了更丰富的关于目的基因在组织器官 发育过程中的功能信息。VHL(von Hippel-Lindau)综 合征发生与 $V H L$ 基因突变有关。 $V h l$ 基因完全剔除小 鼠死于胚胎期。 $\beta$-肌动蛋白启动子指导下的 $C r e$ 重组酶 转基因小鼠制备的 $V h l$ 基因条件打靶 $V H L^{f / d} / C r e$ 小鼠多 个组织的部分细胞中剔除了 $V h l$ 基因, 肝脏发生多发 性血管瘤，多种组织中出现血管扩张和血管生成， 很好地模拟人类疾病的临床特征。有趣的是, 研究 者还发现子代嵌合体雄性小鼠睪丸变小、精子数量 减少并导致不育，表明 $V h l$ 基因还在小鼠精子生成过 程中发挥重要作用 $[41]$ 。

Cre重组酶介导的基因在某些组织器官中的不 完全剔除可以更加精确有效地模拟疾病的发生过 程。部分幼儿粒单系白血病(JMML)患者中发现 $N F 1$ 基因失活的现象。 $\mathrm{Le}$ 等 ${ }^{[42]}$ 将干扰素可诱导的 $\mathrm{Cr} e$ 转基 因小鼠与 $N f 1$ 条件基因打靶小鼠交配，子代 Mxl-Cre; $N f 1^{f l o x f f l o x}$ 条件打靶小鼠仅部分造血细胞中剔除了 $N f 1$ 基因。Nf1 基因的部分失活导致髓系增生障碍，这种 表型相当于JMML的临床亚急性表现。此外, $N f 1$ 基 因的不完全剔除还导致了髓细胞组织浸润、对粒单 集落刺激因子的高敏感性、过度增殖以及抗调亡。 这种可人为调控的小鼠模型对于进行JMML临床治 疗以及 JMML的分子机制深入研究提供了更好的技 术平台。家族性结肠腺瘤性息肉病(FAP)患者携带 $A P C$ 突变基因。Shibata等 ${ }^{[43]}$ 利用腺病毒介导Cre重组 酶在大约 $10 \%$ 20\%的结肠上皮细胞中剔除了 $A p c$ 基 因，结果 $83 \%$ 的 $A p c$ 基因剔除纯合子 $A x C A N C r e$; $A p c^{580 S}$ 小鼠在病毒感染 4 周后发生结肠腺瘤, 平均腺 瘤个数是 6.7 个, $A p c$ 基因剔除纯合子小鼠结肠腺瘤在 1 年后大约 $50 \%$ 发生癌变, 证明了这种小鼠模型可更 好地模拟结肠腺瘤的发生过程。

由于 $C r e$ 转基因小鼠在胚胎干、祖细胞中表达时 相存在差异，这种“嵌合体”表达的条件基因打靶 
在细胞命运和发育谱系的研究应用广泛, 主要是通 过Cre转基因小鼠与报告小鼠(表 1)检测发育不同时 期报告基因的表达来研究。但这种应用需要注意以 下几条: 第一, Cre转基因在胚胎发育整个过程中特 定组织的表达图谱必须明确。时空表达模式图的检 测方法主要是原位杂交和免疫组化, 也可以通过表 达GFP-Cre融合蛋白 ${ }^{[44]}$ 用GFP判定Cre表达的简化方 法; 第二, Cre报告小鼠的时空表达特性需要明确。 通过与Cre报告小鼠表达比较, 可以确定细胞谱系关 系; 第三, 在某时间点检测到的Cre报告基因的表达 应该是所有表达Cre和报告基因的前体细胞的后代。 这些前体细胞可能是同一细胞谱系的不同发育阶段, 也可能是不同的谱系, 仅仅检测发育后期一个阶段 可能会得到错误的细胞命运图。这种缺陷可通过应 用可诱导的条件基因打靶得以解决。一些在分化细 胞中表达的基因, 也可能在胚胎发育的早期有表达, 用这种基因的启动子制备的 Cre转基因小鼠可能由 于胚胎期就开始表达Cre而成为“deleter”小鼠，丧失 其组织/器官的特异性。因此, 选择 Cre转基因小鼠进 行条件基因打靶实验时, Cre开始重组剔除基因的发 育阶段很重要。出生前神经元特异性剔除NMDA受 体 $\mathrm{I}^{[45]}$ 和 TrkB受体 ${ }^{[46]}$ 基因的小鼠都胚胎致死, 只有 通过选择出生后神经元才表达 $\mathrm{Cr}$ 的小鼠来对成年 小鼠的长期记忆形成过程和疾病发生中两种受体的 功能进行解析。

\section{3 生殖系 Cre介导的重组造就表观遗传学对 条件基因打靶的影响}

表观遗传学是指单细胞或者多细胞生物将不是 核苷酸编码的信息遗传给后代的现象。现在越来越 多的证据表明, 转基因动物的卵子或精子中的RNA 或蛋白质可以遗传给非转基因的后代引起表观遗传 学改变。Matthaei等 ${ }^{[47]}$ 在将Tnap 启动子调控的Cre小 鼠和 FloxStop (基因结构为loxP- $\beta$-gal-Stop-loxP$E G F P)$ 小鼠交配时最直观地发现了这一问题。

FloxStop小鼠表达 $\beta-G a l$, 由于STOP序列的存在而不 表达GFP。和Cre小鼠交配后的双转基因条件表达小 鼠( (delLoxP)因为 $\beta-G a l$ 的剔除, 不再表达 $\beta-G a l$, 同时 预期通过这种交配Cre会剔除 $\beta$-gal-Stop 使小鼠开始 表达GFP而变绿。实际上, $C r e$ 转基因是父本时, 确实 看到了 $\mathrm{Cre}$ 稳定遗传给后代并在子代中剔除了针定
的基因(Cre/delLoxP)。雄性野生型Cre阳性小鼠和 FloxStop/FloxStop 雌鼠交配产生的后代全部是 FloxStop 阳性, 一半是Cre阳性。只有Cre阳性子代 小鼠因为停止序列切除 $(\operatorname{delLoxP})$ 而变绿。然而, 当 Cre转基因是母本时, 和FloxStop/FloxStop雄鼠交配 产生的后代也全部是 FloxStop 阳性, 一半是Cre阳 性。但全部子代小鼠都表达GFP而变绿, 即便是没有 遗传获得Cre 基因的WT/delLoxP P朋性小鼠也变绿。其 他科学家也发现了这种现象: 角蛋白 $K 5$ 启动子调控 的 $C r e$ 转基因公鼠用于条件打靶时可以实现组织特 异性基因剔除，而角蛋白 $K 5$ 启动子调控的 $C r e$ 转基 因母鼠的所有后代均发生了基因的剔除 ${ }^{[48]}$, 即便是 没有遗传获得 $C r e$ 基因的小鼠; 更为重要的是 $C r e$ 转 基因小鼠作母本时，子代基因的剔除不再是组织特 异性的条件剔除, 而是所有组织的针定基因全部被 剔除, 表明剔除可能发生在胚胎发育的早期阶段 [48]。这些数据表明, Cre的RNA或者蛋白可能存在于 Cre转基因母鼠的所有卵子中, 能够遗传给非转基 因的后代，引起广泛的基因剔除。而且，这种“母系 遗传”现象发生于其他多种不同的启动子调控的Cre 小鼠 ${ }^{[49 \sim 51]}$ 中, 暗示这种现象可能普遍存在。在这种 情况, 不携带 Cre转基因的floxed 小鼠可能不是一个 严格的对照。

在这种“母系遗传”现象逐步引起人们关注之时， 是否可以应用 $C r e$ 公鼠和基因针定的母鼠进行交配 避免这种现象呢? 最近的一项研究 ${ }^{[52]}$ 否定了这种设 想, 他们应用 $3.6 \mathrm{~kb}$ 或 $2.3 \mathrm{~kb}$ 大鼠Collal 启动子调控 的Cre转基因小鼠(Col3.6-Cre和 Col2.3-Cre)与 Igfl 第 4 外显子被锚定的小鼠交配制备成骨细胞特异性的 Igfl 打靶小鼠, 结果发现部分没有遗传 Cre 基因的后 代小鼠也发生了 I $g f 1$ 基因的重组剔除。Col2.3-Cre和 Col3.6-Cre为母本的后代重组发生率分别是 $50 \%$ 和 $28 \%$ 。更为人惊奇的是 Col 2.3-Cre 和 Col3.6-Cre为父 本的后代重组发生率分别是 $15 \%$ 和 $18 \%$ 。这种Cre 的RNA或蛋白质通过精子遗传并引起重组的“父系 遗传”现象同样存在, 只不过效率稍稍低于“母系遗 传”现象。

最近发现了转基因 RNA能够在非转基因子代中 引起表型变化的直接证据。Rassoulzadegan等 ${ }^{[53]}$ 发现, 携带 $K i t^{t m l A l f}$ 转基因的公鼠的腿和尾有白色斑点。这 些小鼠与野生型母鼠交配产生的后代, 包括那些 
$K i t^{t m I A l f}$ 转基因阴性的子代小鼠, 全部具有白色斑点 的腿和尾。更为有趣的是, 他们将 $K i t^{\text {tm I Alf }}$ 的RNA注 射到单细胞的小鼠胚胎, 获得了具有白色斑点的腿 和尾的小鼠。这表明, $K i t^{t m I A l f /+}$ 的RNA能够通过转基因 公鼠的精子遗传给非转基因的后代, 在转基因基因本 身不存在的情况下诱导表型的发生。

各种 $C r e$ 转基因小鼠原则上都应该能够有效介导 小鼠生殖系中 loxP针定序列的重组 ${ }^{[48,54 ~ 57]}$, 否则, 基因打靶突变体小鼠中部分小鼠携带理想的条件打 靶突变基因, 部分小鼠大部分机体细胞乃至所有细 胞的基因都可能被剔除，呈现不均一性。这种不均 一性可能完全掩盖真实的实验结果, 主要依赖于条 件打靶小鼠是否能够从它的父本和母本同时遗传获 得loxP针定的等位基因和 $C r e$ 转基因。因此, 涉及到 Cre重组酶介导种系重组的研究, 必须事先煁酌好小 鼠交配的方法, 以保证 $C r e$ 等位基因和LoxP针定的 等位基因来源于不同的父本母本。

这些数据强烈地提示我们在用同窝非 Cre 转基 因小鼠作为对照前, 必须记住配子(包括精子和卵子) 中针定的基因能够与来源于 $\mathrm{Cr}$ 转基因小鼠的配子 形成合子后发生 Cre 重组酶介导的重组反应, 即便 是 Cre 转基因小鼠的配子不携带 Cre 转基因也可能 发生, 因此必须仔细比对与野生小鼠的差异。

\section{Cre 重组酶的毒性}

\subsection{Cre 重组酶毒性产生原因及表现}

应用 $\mathrm{Cre}$ 重组酶的条件基因打靶更为重要的一 个潜在的问题是Cre重组酶本身的毒性。Capecchi研 究小组发现Cre能够引起细胞基因组DNA发生重组, 表现出细胞毒性。Prm1 启动子调控精子细胞在有丝 分裂期后表达 Cre, 导致受精卵流产, 外显率为 $100 \%$, 同时伴随大量的DNA损伤，特点为雄原核染 色体呈现“杂乱的DNA”[58]。以同样方式构建的没有 酶活性的 $C r e$ 突变体载体, 和野生型 $\mathrm{Cr}$ 相近表达剂 量的Cre突变体并不会造成DNA损伤, 证明DNA损 伤的确是 Cre重组酶的活性造成的。

另一方面, 哺乳动物基因组中存在隐含的/假的 loxP的序列, 其序列可能和loxP的保守序列不完全 相同, 但能够被Cre重组酶识别而发生重组 ${ }^{[59]}$ 。生物 信息学分析表明小鼠的基因组中大约每百万碱基对
中含有 1.2 个这样的位点 ${ }^{[60]}$ 。Cre重组酶与这些隐含 的识别序列的结合力虽然可能大大低于与保守的 loxP位点的结合力 ${ }^{[59]}$, 但Cre重组酶仍然可以介导两 个隐含的 loxP 位点间的重组; 或者在单个隐含的 loxP位点阻断细胞DNA损伤修复元件的功能, 从而 与DNA共价连接, 成为重组反应的副产物。这些都 能引起DNA的损伤。

很多研究人员已经应用逆转录病毒转染成纤维 细胞的方法仔细研究了 Cre 重组酶的毒性, Cre重组 酶的高水平稳定表达诱导细胞生长停滞 ${ }^{[61 ~ 64]}$, 染色 体异常 ${ }^{[62,64]}$ 。大部分发表的文献中 $C r e$ 转基因小鼠表 型正常, 与野生型小鼠基本难以区分。这种现象令 人费解, 可能的原因是成纤维细胞将细胞中DNA的 断裂和缺口的修复作为生命过程中内在的机制, 造 就了更为精细的修复系统, 从而比其他的细胞(如淋 巴细胞 $\left.{ }^{[63]}\right)$ 对 Cre的毒性更为敏感。其实许多 Cre转基 因小鼠并非完全正常，只是在发育过程中通过选择 和适应消除了 $\mathrm{Cre}$ 的毒性。

\section{2 减少 Cre 重组酶毒性的途径}

采用病毒介导Cre基因表达制备条件基因打靶 的方法 ${ }^{[43]}$ 最大的优点是简单易行。用复制缺陷型腺 病毒瞬时表达的Cre, 能够在成纤维细胞中有效介导 loxP针定的新霉素抗性表达框的切除，但不造成明 显的DNA损伤的病毒浓度范围很大 ${ }^{[65]}$, 这提示通过 控制重组酶的表达时间，只要表达足够量的Cre用以 介导loxP针定的靶基因的重组，就可以降低Cre的细 胞毒性, 至少在成纤维细胞中如此。但这种方式的 缺点显而易见, 那就是 Cre 基因的表达调控太不精 确。此外, 病毒感染可能会引起并发症而干扰小鼠 表型分析。

减少细胞中 Cre重组酶的作用时间的第二种策 略是应用自我切除型 $C r e$ 表达载体 ${ }^{[61,62,66]}, C r e$ 两侧用 loxP针定, 表达的Cre重组酶重组切除自身的表达框 架, 从而终结自身的表达。这种策略的设计技巧在 于用突变的 loxP位点针定 Cre 表达框, 用野生型的 loxP位点针定靶基因, 可以使 $\mathrm{Cre}$ 介导自身切除的效 率低于靶基因的切除，从而保证Cre表达后能够有时 间完成“真正的”重组。

可透膜的Cre重组酶首先是Jo等 ${ }^{[67]}$ 将FGF4 蛋白 12 个氨基酸残基的核定位信号序列(NLS)与Cre重组 
酶构建成融合蛋白NLS-Cre-MTS, 氨基端的NLS可 使 Cre重组酶穿越核膜进入核内发挥作用, 在培养的 细胞中成功地切除了被loxP针定的序列。通过腹腔 注射可透膜的Cre重组酶, 在小鼠的各组织内均检测 到Cre重组酶的活性。这种方法的优势是简单易行, 而且在非增殖终末分化细胞中也可成功实现 Cre重 组酶介导的重组。此方法的缺点是Cre重组酶介导发 生重组的细胞所占比例较少。来源于HIV-TAT的碱 性肽段与 Cre融合形成的透膜型Cre重组酶TATCre, 也可以用于剔除针定的基因, 能够控制条件基因打 靶的时间，而且不用制备并鉴定众多的Cre转基因 系。透膜的Cre重组酶蛋白直接注射到小鼠体内反映 出这种方法的另一种缺陷, 即不具有良好的组织特 异性。Cre通过蛋白转导方法直接导入携带loxP针定 的靶基因的细胞中 ${ }^{[68,69]}$, 这种方法仅仅限于细胞培 养实验。最近, Peitz 等 ${ }^{[70]}$ 发现改进型透膜的 His-TAT- NLS-Cre(简称HTNCre)转导的ES细胞能够 维持正常的核型, 并能进入种系遗传。同理, Patsch 等 ${ }^{[711}$ 最近研制成功透膜的FLP重组酶。

可诱导的Cre表达系统, 主要包括I型干扰素系 统、四环素系统、它莫西芬系统等 ${ }^{[2]}$, 能够改变常规 Cre介导的一次性的不可逆重组过程, 实现Cre的时 空特异性调控, 减少细胞中Cre重组酶的作用时间。

这种可诱导系统不仅能够实现组织特异性的条件基 因打靶, 其更大的优势在于能够在特定的时间通过 给予诱导剂实现条件打靶的时间控制, 避免了C $\mathrm{Cr}$ 重 组造成发育早期的基因缺失造成胚胎期致死表型或 者代偿机制的激活使表型解析复杂化, 彻底改变常规 转基因小鼠Cre进行基因打靶不可逆的缺点。但任何诱 导系统还不能达到一种理想的诱导状态一一没有诱 导的情况下完全没有Cre活性，诱导后能够 $100 \%$ 剔 除靶基因。靶细胞中部分基因剔除产生的嵌合现象 依然存在。四环素系统没有被广泛应用于调控Cre介 导的基因条件打靶的原因似乎就是四环素系统经常 出现“渗漏”。Loonstra等 ${ }^{[64]}$ 用成纤维细胞在内源的 Rosa26 启动子调控Cre和雌激素受体配体结合区的 融合蛋白 (CreERT) 的表达。成纤维细胞在长(达 9 天的)时间、低浓度的它莫西芬诱导下能有效切除 loxP针定的靶基因, 没有发生细胞生长停滞。当然, 完全的靶基因剔除影响了成纤维细胞的扩增。作者 还发现重组反应和Cre毒性与细胞增殖密切相关 ${ }^{[64]}$ 。
有趣的是转基因果蝇中增殖和Cre诱导的发育异常 正相关 ${ }^{[72]}$ 。Raffel等 ${ }^{[73]}$ 试图用它莫西芬诱导的 CreERT2 系统分析活体内B细胞受体在c-Myc转化的 $\mathrm{B}$ 细胞淋巴瘤维持和进展中的作用, 实验最后归于 失败, 其原因在于尽管实验设计时预先排除了会引 起B细胞受体的剔除, 但能够有效介导靶基因重组 的所需浓度的它莫西芬通过CreERT2 足以消除淋巴 瘤。值得注意的是, 对肿瘤细胞的毒性不是它莫西 芬自身, 而是由于CreERT2 的表达 ${ }^{[4]}$ 。CreERT2 融合 蛋白是否是因为ERT2 配体结合区招募自身进入转 录复合体而加剧毒性还需进一步鉴定。最近实验发 现体内表达CreERT2 直接引起血液学毒性和染色体 重组 ${ }^{[74]}$ 。这些结果清楚地表明Cre重组酶是一种浓度 依赖性DNA损伤因子, 对哺乳动物细胞具有毒性作 用。同时, 诱导剂本身可能引起细胞毒性。小鼠能 够耐受单剂量的 4-羟基-它莫西芬, 但长期给予小鼠 4-羟基-它莫西芬会引起严重的毒性作用, 特别是对 肝脏损伤最严重。因此, 条件基因打靶前系统评估 4-差基-它莫西芬的毒副作用具有重要意义。

配体诱导二聚化技术(DiCre系统)最近研制成功 [75], 更为严谨地调控Cre重组酶的体内表达。在这种 方法中, Cre与FKBP12 的FK506 结合域相融合或与 FKBP12 -雷帕霉素相关蛋白FRB的结合域融合生成 两种无活性的Cre融合蛋白。雷帕霉素诱导两种Cre 融合蛋白形成异源二聚体而重建 Cre重组酶活性。该 DiCre系统已用于ES细胞Cre的活性以及小鼠胚胎和 成体组织, 还可以用来建立条件性Cre的“ Deleter” 老鼠。此技术提供了一种组合的方式来调控Cre重组, 可以在任何特定时间点或者细胞类型通过从两个不同 的启动子调节融合蛋白的表达来实现对Cre活性的严 谨调控。该系统另一额外优势在于能克服在哺乳动物 基因组隐藏的loxP位点可能会导致不必要的Cre介导 的染色体重排引发的毒性问题。

\subsection{Cre 转基因可能造成“Cre 毒性” 假象}

除了 Cre重组酶自身的毒性外, 和其他转基因 一样, 随机整合的 $C r e$ 转基因可能会改变整合位点 及其附近的内源基因的表达(插入突变)。这些改变可 能是 Cre转基因的直接插入造成的内源基因的破坏 和/或 $C r e$ 转基因载体携带的启动子、增强子、拼接 
调控序列、多聚A尾巴等影响了内源基因的表达。最 近发现基因组中存在大量功能尚不清楚的非编码区 序列, 它们并非“垃圾DNA”，而是具有重要调控功 能的序列。如果 $C r e$ 转基因插入破坏这些基因编码区 外的序列, 同样可能引起小鼠表型的改变。实际上, 一些 $C r e$ 转基因确实表现出明显的异常表型, 如用 于分析胰腺 $\beta$ 细胞基因功能的RIP-Cre小鼠不能耐受

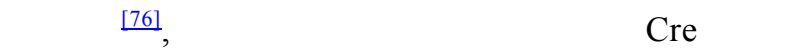
因的插入效应还是两者兼而有之尚不明确。与之相 反, 许多 Cre 编码区定位打靶敲入内源基因位点制 备的小鼠是杂合子基因剔除，基因的剂量效应开始 显现。和野生型小鼠的B细胞相比, CD19-Cre转基因 杂合子小鼠的B细胞表达一半剂量的CD19, 这些小 鼠 $\mathrm{B}$ 细胞发育初级过程似乎正常, 但腹膜 $\mathrm{B} 1$ 细胞的数 量稍有下降 ${ }^{[4]}$, 这些结果与CD19 的表达变化影响B细 胞的选择和功能的结果 ${ }^{[77]}$ 相一致。

\section{5 条件基因打靶的育种策略}

最基本的条件基因打靶的育种策略图见参考文 献[78]。组织或细胞特异性表达Cre重组酶的转基因 小鼠与floxed小鼠交配时，两代后可以得靶基因的 一条等位基因被剔除，另外一条等位基因被针定， 并且在特定组织或细胞表达 Cre重组酶的小鼠，基因 型为 $C r e /+;$ floxed $/ \Delta$, 得到的机率是 $25 \%$, 其前提 是被锚定的等位基因与 $\mathrm{Cr} e$ 基因并不连锁。被剔除的 这条等位基因可来自完全基因剔除小鼠，也可来自 Cre介导的去除篮选标记的副产物-I型缺失。许多情 况下，第二代的怀孕母鼠(F2)经常被处死, 取F3 代 胚胎用于条件基因打靶研究。因此 $C r e /+; \Delta /+$ 小鼠 通常是公鼠，而靶基因两条等位基因被锚定的纯合 floxed/floxed针定小鼠通常是母鼠。这样可以不用鉴 定实验过程中经常处死的纯合针定小鼠。如果没有 靶基因被剔除的小鼠，也可用靶基因一条等位基因 被针定的小鼠(Cre/+; floxed $/+$ )代替靶基因一条等位 基因被剔除的小鼠 $(\mathrm{Cr} e /+; \Delta /+)$ 和纯合锚定小鼠交 配。但这样做, 就需要 $\mathrm{Cr}$ 重组酶有较强的活性, 因 为 F3 代小鼠两条被针定的靶基因都需在 $\mathrm{Cr}$ 重组酶 的作用下被条件剔除。最近Zhao 等 ${ }^{[79]}$ 应用这种简化 策略获得的 $\alpha G S U-C r e ; S f I^{f f f}$ 小鼠具有下垂体特异的 亚效等位基因表型。另外, $C r e /+; \Delta /+$ 小鼠交配可得
到基因型为 $\mathrm{Cre} / \mathrm{Cre} ; \Delta /+$ 的小鼠，这种小鼠与 floxed/floxed 小鼠交配可使得到条件基因剔除F3 代 小鼠的机率提高到 $50 \%$ 。但要注意的是, Cre重组酶 位点纯合的小鼠表型是否为野生型的表型。通过基 因敲入方法制备的 $C r e$ 转基因小鼠通常不是野生型 表型，因为 $C r e$ 引入的同时伴有基因剔除的发生。育 种计划并非完全如上所述一成不变, 而要根据小鼠 的遗传背景、不同基因型小鼠的生育率和存活率等 来决定。

研究隐性胚胎致死突变小鼠时，通过杂合子育 种途径获得纯合子条件打靶小鼠的几率仅占子代小 鼠的四分之一。除了这种效率低的缺陷, 每一个胚 胎还都需要进行基因型鉴定。当需要大量的突变体 胚胎进行实验时, 收集足够的样品所需的时间和财 力物力将成为一大障碍。当然, 可以用大量的人力 和充足的空间进行大规模的小鼠交配来获得突变体, 但实验动物的 $3 R$ 原则和资金的要求还是需要研究 者做出合理的实验设计。一种生殖细胞特异性条件 打靶育种策略可以提高获得条件打靶小鼠的孟德尔 遗传比例。原理上讲, 生殖细胞特异表达Cre并携带 针定靶基因的小鼠将只产生基因剔除的配子，这两 种小鼠交配产生的后代将全部是基因剔除的小鼠。 实际上, 卵子特异的Zp3-Cre/+; Sox $9^{\text {floxfllox }}$ 母鼠与精 子特异的Prm 1-Cre/+; Sox $9^{\text {floxflox }}$ 公鼠交配的后代 $75 \%$ 为 $\operatorname{Sox} 9^{\Delta / \Delta}$ 条件剔除，而 $25 \%$ 为 $\operatorname{Sox} 9^{\Delta / f l o x}$ 。Sox 9 基 因剔除杂合缺失导致小鼠死亡。可以想象, 单倍体 致死小鼠很难用于获得纯合子。这种策略实际上避 免了单倍体致死, 但还没有见到用于提高突变体比 例的报道 ${ }^{[80]}$ 。

\section{6 条件基因打靶的实验对照}

Cre重组酶的毒性问题的存在是文献中已经证 明的，但在条件基因打靶这一领域多被忽略。近期 一项应用RIP-Cre 小鼠的综合分析 ${ }^{[76]}$ 表明，大部分 研究者没有设立只携带 $C r e$ 转基因而靶基因没有被 针定的小鼠这种必要的严格对照, 这种省略将导致 严重的错误实验数据。Naiche等 ${ }^{[81]}$ 仔细检测了 3 种 曾经报道过的 $\mathrm{Cr}$ 小鼠系, 发现 $\mathrm{Cr}$ 重组酶本身足以 引起严重的发育缺陷, 其中 2 种 $C r e$ 转基因小鼠系造 血功能丧失, 许多胚胎组织细胞凋亡明显增加, 表 
明Cre重组酶的毒性表达会造成假象, 影响表型遗传 学分析的准确性。特别是应用这些小鼠的研究报道 并没有设立 $C r e$ 转基因小鼠作为阴性对照, 因此条 件基因打靶小鼠的表型全部归处于靶基因的功能缺 失。实际上, 部分或者全部表型的出现是 $\mathrm{Cre}$ 重组酶 毒性造成的, 这提示我们需要仔细评估以前发表的 条件打靶实验, 谨慎细致地设计以后的条件打靶实 验。

在条件基因打靶实验中即便设立 Cre 转基因的 小鼠或细胞作为常规对照, 这样的对照实验未必能 完全解决问题的存在, 因为 Cre 毒性可能只有通过 打靶引入突变后才显现出来, 而自身并没有毒性作 用, 比如 Cre 重组酶介导的抗调亡基因或 DNA 损伤 相关基因的剔除会导致中靶细胞的调亡, 因为它们 不能继续抵抗 Cre 重组酶的毒性作用。当 Cre 重组 酶介导引入一个致癌突变时, 也无法简单地排除 DNA 损伤造成稀有细胞的转化。很明显, 这时可以 尝试控制 Cre 重组酶在细胞内表达的时间, 或者应 用挽救实验来逆转打靶突变。

\section{7 条件基因打靶小鼠的遗传背景}

遗传背景被定义为能够和目的基因相互作用的基 因组中全部其他基因并能潜在影响表型的基因型 ${ }^{[82]}$ 。 因此, 条件基因打靶实验中遗传背景也是个值得关 注的问题, 因为它不仅可能影响主要的病理表型, 还会影响条件打靶系统本身的效率。不同小鼠品系 中 rtTA系统的调控也不相同为此提供了证据 ${ }^{[83]}$ 。尽 管目前还没有系统的研究, 但据此类推, 不同的Cre 介导的基因打靶可能也是小鼠品系依赖性的。自然 界存在的这种复杂性可能造成难以预料的结果或者 将误导我们的研究，特别是不同的近交背景下不同 的条件小鼠杂交造成遗传多重性时影响更为严重。 基于此, 许多实验者主张实验过程中需要尽力保持 纯的小鼠遗传背景。

只是最近大鼠ES细胞来源的基因敲除才被成功 报道 ${ }^{[84]}$, 在此之前, 动物中只有小鼠的ES细胞能够 种系遗传, 而且是仅仅来源于几个品系的小鼠。小 鼠的ES细胞最早来源于 129 系小鼠, 构建floxed小 鼠时由于其种系遗传性、易于遗传操作和扩增等优 点应用最为广泛。但 129 系小鼠存在以下 3 方面的
问题需要引起注意: 首先, 129 系小鼠由于内在的遗 传缺陷, 繁殖能力极差, 因此, 实验中难以保持简 单的同类系遗传背景; 其次, 129 系小鼠常伴有神经 解剖学和行为学缺陷。与B6 小鼠相比, 129 小鼠的理 毛行为、空阔场地的活动和习惯、运动能力和运动 学习、记忆、恐惧、抑有样行为、焦虑、药物反应 等生理参数完全不同 ${ }^{[85]}$, 因此应用条件打靶进行神 经生物学研究时遗传背景显得更为重要; 第三, 129 系小鼠存在 $129 / \mathrm{J} 、 129 / \mathrm{Sv} 、 129 / \mathrm{SvEv}$ 以及 $129 / \mathrm{Ola}$ 等亚型, 不同亚型之间的遗传变异造成不同的生理 和行为表现。经常会发现用同一个打靶载体, 在不 同的遗传背景下进行打靶，获得的小鼠表型却有很 大差别。因此, 在实验设计、特别是打靶小鼠表型 分析时, 一定要考虑到这些差异的存在。可喜的是, 特定区域的单核苷酸多态性检测能够准确区分这些

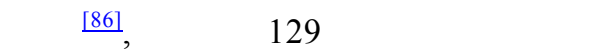

为制备基因打靶小鼠，一般在 129 系小鼠 ES 细 胞中引入突变, 考虑到应用毛色直接判断定嵌合体 小鼠的方便，中靶 ES 细胞注射到 C57BL/6(B6)囊胚， 获得棕、黑杂色的嵌合体小鼠，这种可种系遗传的 嵌合体小鼠产生的后代为 129:B6 杂合背景。为消除 遗传背景对于小鼠表型分析造成的影响，一般重复 回交至理想的遗传背景之中。回交遗传背景通常选 择 B6。B6 在打靶小鼠被广泛应用的原因主要是繁 殖力强, 比 129 系具有更少的生理和行为异常表型。 通过至少 10 代的回交，同类系可以达到 $99.9 \%$ 的 B6 背景，但永远不能完全恢复 100\%的 B6 背景，因为 在基因突变位点或转基因整合位点附近的染色体总 包含至少几百个侧翼基因与突变基因或转基因连锁, 侧翼基因与突变基因距离越近, 染色体交换时相互 分离的几率越小, 连锁就越紧密, 因此这些连锁基 因的遗传学来源是不确定的。同时, 这种回交需要 的时间可能达两年之久, 因此通常的做法就是开始 实验时就采用遗传背景一致的小鼠。另外, 显微注 射法制备的 Cre 转基因小鼠的背景的选择通常是由 不同遗传背景的小鼠超排能够获得的卵子的数量和 质量来决定。在特定遗传背景下的 Cre 转基因小鼠 与 129 或 129/B6 杂合遗传背景下针定基因的小鼠交 配进行条件打靶，这种技术本身也会造成混杂遗传 背景。 
替代 129 系的惟一选择是B6。如果能从B6 背景 的小鼠分离几种具有生成嵌合体和种系遗传能力的 ES细胞, 将取代 129 系ES细胞，从而使B6 成为基因 打靶和显微注射的主要遗传背景 ${ }^{[87]}$ 。其实, 早在 1991 年, 第一株B6 ES细胞系就已建立 ${ }^{[88]}$, 但是和 随后的几株都没有被成功得以推广应用, 主要原因 是B6 ES细胞技术方面的障碍 ${ }^{[89]}$, B6 系ES细胞难以 培养, 标准培养条件下染色体不稳定, 易于产生非 整倍体。表达芯片分析 ${ }^{[90]}$ 表明培养中的B6 系ES细胞 比 129 系ES细胞更易于失去全能性。B6 系ES细胞产 生种系嵌合体的效率比 129 系弱, B6 与 129/S5 系ES 细胞的嵌合效率分别为 43\%和 $81 \%$ [91]。目前正在进 行的国际基因剔除协会 (IKMc), 主要包括美国的 剔除小鼠计划 (KOMP)、欧洲的条件小鼠突变 (EUCOMM)和加拿大的北美条件小鼠突变, 一致同 意应用相同的C $57 \mathrm{BL} / 6 \mathrm{~N}$ 遗传背景的ES细胞系进行 [92], 主要的目的就是完全消除遗传背景对小鼠表型 的影响, 使基因功能的分析简单化。已经有实验室 成功分离了 $\mathrm{B} 6$ 小鼠的 ES细胞, 并构建了多种基因针 定小鼠和 $C r e$ 转基因小鼠 ${ }^{[93]}$, 还有实验室建立了 $\mathrm{B} 6$ 背景的 Flp 转基因小鼠 ${ }^{[94]}$, 从而可以在单一的B6 遗 传背景下进行条件基因打靶研究机体生理和病理的 分子机制。C $57 \mathrm{BL} / 6 \mathrm{~N}$ 系ES细胞培养体系的优化以及 种系嵌合体的制备技术的成熟将加速大规模基因条 件打靶计划的完成 ${ }^{[95]}$, 必将对小鼠实验生物学研究 产生深远的影响。

遗传背景的不同使小鼠的表型的解析变得复杂 的同时, 也为我们分析突变的研究提供了机会。条 件基因打靶小鼠最初的制备和保种通常是在杂合背 景下(B6 和 129 打靶小鼠或 B6 和 SJL 的 Cre 转基因 小鼠), 进一步育种和回交可能会得到与杂合背景小 鼠完全不同的表型, 甚至可能从胚胎致死表型变成 能存活到出生后的转变。另有原因支持选择杂合背 景: 回交消除杂合背景的周期较长; 许多品系特异 性的隐性等位基因导致一些小鼠的表型分析实验难 以辨认, 能通过不同品系的等位基因杂合消除这种 影响, 有些表型在杂合小鼠中比近交系小鼠中差异 要小。

\section{8 双/多基因条件基因打靶}

在发育、生理和疾病的过程中, 多种遗传学信
号通路连续或者平行地或交织发挥功能。常规的打 靶突变体很难用于探究出它们之间的相互调节与关 联。在突变遗传背景下的组合多基因条件打靶为探 讨特定生物学过程中不同信号途径之间的相互作用 提供了研究的平台。现在, 越来越多的双/多基因条 件打靶小鼠用于研究复杂的信号转导通路以及各种信 号通路之间的互作来解析复杂的生理和病理机制。

Jonkers等 ${ }^{[96]}$ 最先应用 Brac2 和 $p 53$ 双基因条件 打靶小鼠研究了上皮细胞特异性条件基因剔除在肿 瘤发生中的作用。他们将抑癌基因Brca2(针定外显 子 11)和/或 $p 53$ (针定外显子 2-10)小鼠与上皮特异性 K14-Cre 小鼠交配，Brca2 条件剔除 K14Cre; $B r c a 2^{\mathrm{F} 11 / \mathrm{F} 11}$ 小鼠没有肿瘤发生, 而Brac2 和 $p 53$ 双基 因剔除 $\mathrm{K} 14 C r e ; B r c a 2^{\mathrm{F} 11 / \mathrm{F} 11} ; \operatorname{Trp} 53^{\mathrm{F} 2-10 / \mathrm{F} 2-10}$ 母鼠发生 乳腺肿瘤和皮肤肿瘤, 证明 Brac2 和 $p 53$ 两基因的剔 除共同介导乳腺肿瘤的发生，二者具有协同作用。

多基因条件打靶还可以解决是否存在基因冗 余。一个很著名的例子可见于加州大学的发育生物 学家Martin及其同事的工作 ${ }^{[97]}$ 。外胚层嵴尖(AER) 产生信号控制肢体近端-远端轴的发育。成纤维细胞 生长因子 (FGF) 是重要的细胞因子, 但有 4 种 FGF(FGF4、FGF8、FGF9、FGF17)在小鼠的AER表 达, 很难研究它们的功能。解决的办法就是得益于 应用Msx2-Cre在小鼠肢体条件敲除不同组合的 $F g f$, 从而解析出每一种FGF对整个AER-FGF 信号的作 用。她们发现, Fgf $4 / 9 / 17$ 三基因条件打靶小鼠的肢 体骨骼和野生型类似，而只有 Fgf8 是正常肢体发育 所必需的。其余 3 种 $F g f$ 的功能是几余的吗? 和单独 的 $F g f 8$ 条件打靶小鼠相比, 一系列 $F g f 8$ 与其他 3 种 $F g f$ 基因中一种或多种的组合条件打靶小鼠表型不 同程度地加重, 说明AER产生的 4 种FGF全部作用 于肢体的图式形成同一信号通路, 但作用强度不 同。这种独特的遗传学研究解决了困扰多年的难题, 革新了多年来人们传统的发育学理论。

需要注意的是, 如果多基因条件打靶小鼠两个 不同的基因携带 4 个loxP位点可能会导致染色体重 组。减少这种重组的一种方法是其中一个基因用经 典的loxP位点针定, 另一个基因用突变的loxP针定, 因为经典的1 $0 x P$ 位点和突变的loxP位点之间的重组 效率大大降低。突变的loxP可以用于针定特定的外 显子, Cre介导针定序列的颠倒, 而不是剔除外显子, 
结果用突变的外显子置换了野生型外显子。为使这 种颠倒不可逆转, 可以在上游 loxP位点( loxP1) 和下 游loxP位点(loxP2)引入多种点突变。重组后生成的 $\operatorname{lox} \mathrm{P}$ 位点( loxP1、loxP2)含有两个原始loxP位点的突 变, 将大大降低重组效率 ${ }^{[98]}$ 。

\section{9 不用组织特异性重组酶实现组织特异性 条件基因打靶}

小鼠基因的表达调控逐渐明确，不仅有利于制 备更多的组织/细胞特异性的 Cre转基因小鼠用于条 件基因打靶, 也为不用组织特异性重组酶而实现组 织特异性条件基因打靶提供了可能。Terauchi等 ${ }^{[99]}$ 应 用常规的基因打靶方法剔除了葡萄糖激酶基因在胰 腺 $\beta$ 细胞中特异的可变拼接外显子 1 , 从而在胰腺 $\beta$ 细胞中特异剔除了葡萄糖激酶基因, 而肝细胞中没 有剔除，实现了条件打靶。Norris等 ${ }^{[100]}$ 定位并靶向 破坏了Nodal基因非对称表达的增强子, 改变了该基 因在神经节和侧板中胚层非对称性表达的模式。随 着小鼠基因组测序的完成，基因表达调控的逐步深 入以及转基因小鼠的制备, 这种不通过和 $\mathrm{Cr} e$ 转基 因小鼠交配而实现条件打靶研究基因来研究不同的 组织/细胞中的多种功能将成为现实。

最近发展起来的基因组靶向改造的系统应用了 锌指核酶。锌指核酶最初设计用来进行基因治疗 ${ }^{[101]}$, 包含一个锌指DNA结合结构域和一个DNA切割结 构域/限制性内切酶, 不同的锌指结构域决定特异性 的DNA断裂位点的特异性, 因为每个锌指与特定的 DNA三碱基对结合。不同的锌指组合能够识别并结 合 9 12 bp的基序。锌指核酶在特定的基因位点制造 出双链断裂。断裂缺口可以通过与锌指核酶共转的 染色体外DNA供体序列同源重组修复, 这样, 供体 序列携带的任何突变或挽救都能够导入基因组中。 断裂缺口也可以通过简单的非同源末端连接的增加 或删除碱基引入突变。锌指核酶技术已经成功用于 内源基因的敲除和外源基因的表达 ${ }^{[102]}$ 。

\section{0 展 望}

理论上，研究人员可以选择任意特定的组织或 时间实现条件基因打靶, 而选择重组系统时主要依 赖于研究的目的和本实验室专长的实验技术，除非
是特殊需要, 首选的还应该是那些已经成熟并广为 应用的系统。条件打靶实验需要大量的资源和较长 的时间周期，而且无法保证实验的成功。虽然很多 问题有待解决，诸如嵌合体、Cre的异位或渗漏等不 保真表达、Cre转基因表达模式需要精确分析(如应 用可靠的报告小鼠或敲入报告基因)等，但多种条件 基因打靶体系(如Cre-LoxP、Flp-FRT、可诱导系统 等以及最近发明的Dre-rox系统 $\left.{ }^{[103]}\right)$ 的完善将使更加 复杂的结合实验实现精细条件打靶显示出更广更深 的应用前景。大规模小鼠全基因组的条件基因打靶 计划中应用同一遗传背景可以消除遗传背景对条件 基因打靶小鼠表型的影响。虽然条件基因打靶技术 在完全基因剔除的基础上已有长足进步，但如何对 条件基因打靶在时间上和空间上进行更为精细的调 控仍然需要进一步研究和探索。我们相信, 各种Cre 重组酶工具小鼠的不断完善，越来越多的条件基因 打靶小鼠的建立必将使得条件基因打靶技术在现代 生物医学研究各个领域发挥越来越大的作用。

\section{参考文献(References):}

[1] Glaser S, Anastassiadis K, Stewart AF. Current issues in mouse genome engineering. Nat Genet, 2005, 37(11): 1187-1193.DOI

[2] Branda CS, Dymecki SM. Talking about a revolution: The impact of site-specific recombinases on genetic analyses in mice. Dev Cell, 2004, 6(1): 7-28. DOI

[3] Rajewsky K, Gu H, Kühn R, Betz UA, Müller W, Roes J, Schwenk F. Conditional gene targeting. J Clin Invest, 1996, 98(3): 600-603. DOI

[4] Schmidt-Supprian M, Rajewsky K. Vagaries of conditional gene targeting. Nat Immunol, 2007, 8(7): 665-668. DOI

[5] Matthaei KI. Genetically manipulated mice: a powerful tool with unsuspected caveats. $J$ Physiol, 2007, 582(Pt 2): 481-488.

[6] Holzenberger M, Lenzner C, Leneuve P, Zaoui R, Hamard G, Vaulont S, Bouc YL. Cre-mediated germline mosaicism: a method allowing rapid generation of several alleles of a target gene. Nucleic Acids Res, 2000, 28(21): E92. DOI

[7] Rickert RC, Roes J, Rajewsky K. B lymphocyte-specific, Cre-mediated mutagenesis in mice. Nucleic Acids Res, 1997, 25(6): 1317-1318. DOI

[8] Soriano P. Generalized lacZ expression with the ROSA26 Cre reporter strain. Nat Genet, 1999, 21(1): 70-71. DOI

[9] Tsien JZ, Chen DF, Gerber D, Tom C, Mercer EH, Ander- 
son DJ, Mayford M, Kandel ER, Tonegawa S. Subregionand cell type-restricted gene knockout in mouse brain. Cell, 1996, 87(7): 1317-1326. DOI

[10] Akagi K, Sandig V, Vooijs M, Van der Valk M, Giovannini M, Strauss M, Berns A. Cre-mediated somatic site-specific recombination in mice. Nucleic Acids Res, 1997, 25(9): 1766-1773. DOI

[11] Zinyk DL, Mercer EH, Harris E, Anderson DJ, Joyner AL. Fate mapping of the mouse midbrain-hindbrain constriction using a site-specific recombination system. Curr Biol, 1998, 8(11): 665-668. DOI

[12] Mao X, Fujiwara Y, Orkin SH. Improved reporter strain for monitoring Cre recombinase-mediated DNA excisions in mice. Proc Natl Acad Sci USA, 1999, 96(9): 5037-5042. $\underline{\mathrm{DOI}}$

[13] Lobe CG, Koop KE, Kreppner W, Lomeli H, Gertsenstein M, Nagy A. Z/AP, a double reporter for Cre-mediated recombination. Dev Biol, 1999, 208(2): 281-292. DOI

[14] Michael SK, Brennan J, Robertson EJ. Efficient gene-specific expression of Cre recombinase in the mouse embryo by targeted insertion of a novel IRES-Cre cassette into endogenous loci. Mech Dev, 1999, 85(1-2): 35-47.

[15] Novak A, Guo CY, Yang WY, Nagy A, Lobe CG. Z/EG, a double reporter mouse line that expresses enhanced green fluorescent protein upon Cre-mediated excision. Genesis, 2000, 28(3-4): 147-155.

[16] Kawamoto S, Niwa H, Tashiro F, Sano S, Kondoh G, Takeda J, Tabayashi K, Miyazaki J. A novel reporter mouse strain that expresses enhanced green fluorescent protein upon Cre-mediated recombination. FEBS Lett, 2000, 470(3): 263-268. DOI

[17] Mao XH, Fujiwara Y, Chapdelaine A, Yang HD, Orkin SH. Activation of EGFP expression by Cre-mediated excision in a new ROSA26 reporter mouse strain. Blood, 2001, 97(1): 324-326. DOI

[18] Huang ZJ, Yu W, Lovett C, Tonegawa S. Cre/loxP activated neuronal markers in mouse neocortex and hippocampus. Genesis, 2002, 32(3): 209-217. DOI

[19] Braz JM, Rico B, Basbaum AI. Transneuronal tracing of diverse CNS circuits by Cre-mediated induction of wheat germ agglutinin in transgenic mice. Proc Natl Acad Sci USA, 2002, 99(23): 15148-15153. DOI

[20] Vintersten K, Monetti C, Gertsenstein M, Zhang P, Laszlo L, Biechele S, Nagy A. Mouse in red: red fluorescent protein expression in mouse ES cells, embryos, and adult animals. Genesis, 2004, 40(4): 241-246. DOI

[21] Madisen L, Zwingman TA, Sunkin SM, Oh SW, Zariwala HA, Gu H, Ng LL, Palmiter RD, Hawrylycz MJ, Jones AR, Lein ES, Zeng HK. A robust and high-throughput Cre reporting and characterization system for the whole mouse brain. Nat Neurosci, 2010, 13(1): 133-140. DOI

[22] Badaloni A, Bonanomi D, Albieri I, Givogri I, Bongarzone E, Valtorta F, Consalez GG. Transgenic mice expressing a dual, CRE-inducible reporter for the analysis of axon guidance and synaptogenesis. Genesis, 2007, 45(6): 405-412. DOI

[23] Arenkiel BR, Klein ME, Davison IG, Katz LC, Ehlers MD. Genetic control of neuronal activity in mice conditionally expressing TRPV1. Nat Methods, 2008, 5(4): 299-302.

[24] Braz JM, Rico B, Basbaum AI. Transneuronal tracing of diverse CNS circuits by Cre-mediated induction of wheat germ agglutinin in transgenic mice. Proc Natl Acad Sci USA, 2002, 99(23): 15148-15153. DOI

[25] Ishikawa TO, Herschman HR. Conditional bicistronic Cre reporter line expressing both firefly luciferase and $\beta$-galactosidase. Mol Imaging Biol, 2010, 13(2): 284-292. DOI

[26] Rodriguez CI, Dymecki SM. Origin of the precerebellar system. Neuron, 2000, 27(3): 475-486. DOI

[27] Awatramani R, Soriano P, Mai JJ, Dymecki S. An Flp indicator mouse expressing alkaline phosphatase from the ROSA26 locus. Nat Genet, 2001, 29(3): 257-259. DOI

[28] Possemato R, Eggan K, Moeller BJ, Jaenisch R, Jackson-Grusby L. Flp recombinase regulated lacZ expression at the ROSA26 locus. Genesis, 2002, 32(2): 184-186. DOI

[29] Awatramani R, Soriano P, Rodriguez C, Mai JJ, Dymecki SM. Cryptic boundaries in roof plate and choroid plexus identified by intersectional gene activation. Nat Genet, 2003, 35(1): 70-75.

[30] Yamamoto M, Shook NA, Kanisicak O, Yamamoto S, Wosczyna MN, Camp JR, Goldhamer DJ. A multifunctional reporter mouse line for Cre- and FLP-dependent lineage analysis. Genesis, 2009, 47(2): 107-114. DOI

[31] Livet J, Weissman TA, Kang H, Draft RW, Lu J, Bennis RA, Sanes JR, Lichtman JW. Transgenic strategies for combinatorial expression of fluorescent proteins in the nervous system. Nature, 2007, 450(7166): 56-62. DOI

[32] Srinivas S, Watanabe T, Lin CS, William CM, Tanabe Y, Jessell TM, Costantini F. Cre reporter strains produced by targeted insertion of EYFP and ECFP into the ROSA26 locus. BMC Dev Biol, 2001, 1: 4. DOI

[33] Schmidt-Supprian M, Wunderlich FT, Rajewsky K. Excision of the Frt-flanked neoR cassette from the CD19cre knock-in transgene reduces Cre-mediated recombination. Transgenic Res, 2007, 16(5): 657-660. DOI

[34] Opferman JT, Letai A, Beard C, Sorcinelli MD, Ong CC, Korsmeyer SJ. Development and maintenance of B and $\mathrm{T}$ 
lymphocytes requires antiapoptotic MCL-1. Nature, 2003, 426(6967): 671-676. DOI

[35] Thomas MD, Kremer CS, Ravichandran KS, Rajewsky K, Bender TP. c-Myb is critical for B cell development and maintenance of follicular B cells. Immunity, 2005, 23(3): 275-286. DOI

[36] Kmita M, Kondo T, Duboule D. Targeted inversion of a polar silencer within the HoxD complex re-allocates domains of enhancer sharing. Nat Genet, 2000, 26(4): 451-454. DOI

[37] Moon AM, Cappechi MR. Fgf8 is required for outgrowth and patterning of the limbs. Nat Genet, 2000, 26(4): 455-459. DOI

[38] Kraus M, Alimzhanov MB, Rajewsky N, Rajewsky K. Survival of resting mature B lymphocytes depends on BCR signaling via the $\operatorname{Ig} \alpha / \beta$ heterodimer. Cell, 2004, 117(6): 787-800. DOI

[39] Victoratos P, Lagnel J, Tzima S, Alimzhanov MB, Rajewsky K, Pasparakis M, Kollias G. FDC-specific functions of p55TNFR and IKK2 in the development of FDC networks and of antibody responses. Immunity, 2006, 24(1): 65-77. DOI

[40] Zabel MD, Weis JH. Cell-specific regulation of the CD21 gene. Int Immunopharmacol, 2001, 1(3): 483-493 DOI

[41] Ma WB, Tessarollo L, Hong SB, Baba M, Southon E, Back TC, Spence S, Lobe CG, Sharma N, Maher GW, Pack S, Vortmeyer AO, Guo CF, Zbar B, Schmidt LS. Hepatic vascular tumors, angiectasis in multiple organs, and impaired spermatogenesis in mice with conditional inactivation of the VHL gene. Cancer Res, 2003, 63(17): 5320-5328.

[42] Le DT, Kong N, Zhu Y, Lauchle JO, Aiyigari A, Braun BS, Wang E, Kogan SC, Le Beau MM, Parada L, Shannon KM. Somatic inactivation of Nf1 in hematopoietic cells results in a progressive myeloproliferative disorder. Blood, 2004, 103(11): 4243-4250. DOI

[43] Shibata H, Toyama K, Shioya H, Ito M, Hirota M, Hasegawa S, Matsumoto $\mathrm{H}$, Takano H, Akiyama $\mathrm{T}$, Toyoshima K, Kanamaru R, Kanegae Y, Saito I, Nakamura Y, Shiba K, Noda T. Rapid colorectal adenoma formation initiated by conditional targeting of the Apc gene. Science, 1997, 278(5335): 120-123. DOI

[44] Heinrich AC, Pelanda R, Klingmüller U. A mouse model for visualization and conditional mutations in the erythroid lineage. Blood. 2004, 104(3): 659-666.

[45] Tsien JZ, Huerta PT, Tonegawa S. The essential role of hippocampal CA1 NMDA receptor-dependent synaptic plasticity in spatial memory. Cell, 1996, 87(7): 1327-1338. $\underline{\mathrm{DOI}}$

[46] Minichiello L, Korte M, Wolfer D, Kühn R, Unsicker K,
Cestari V, Rossi-Arnaud C, Lipp HP, Bonhoeffer T, Klein R. Essential role for TrkB receptors in hippocampus-mediated learning. Neuron, 1999, 24(2): 401-414. $\underline{\mathrm{DOI}}$

[47] Lomelí H, Ramos-Mejía V, Gertsenstein M, Lobe CG, Nagy A. Targeted insertion of Cre recombinase into the TNAP gene: excision in primordial germ cells. Genesis, 2000, 26(2): 116-117. DOI

[48] Ramirez A, Page A, Gandarillas A, Zanet J, Pibre S, Vidal M, Tusell L, Genesca A, Whitaker DA, Melton DW, Jorcano JL. A keratin K5 Cre transgenic line appropriate for tissue-specific or generalized Cre-mediated recombination. Genesis, 2004, 39(1): 52-57. DOI

[49] Hayashi S, Tenzen T, McMahon AP. Maternal inheritance of Cre activity in a Sox2Cre deleter strain. Genesis, 2003, 37(2): 51-53. DOI

[50] Vincent SD, Robertson EJ. Highly efficient transgene-independent recombination directed by a maternally derived SOX2CRE transgene. Genesis, 2003, 37(2): 54-56. DOI

[51] Sakai K, Miyazaki J. A transgenic mouse line that retains Cre recombinase activity in mature oocytes irrespective of the cre transgene transmission. Biochem Biophys Res Commun, 1997, 237(2): 318-324. DOI

[52] Cochrane RL, Clark SH, Harris A, Kream BE. Rearrangement of a conditional allele regardless of inheritance of a Cre recombinase transgene. Genesis, 2007, 45(1): 17-20. DOI

[53] Rassoulzadegan M, Grandjean V, Gounon P, Vincent S, Gillot I, Cuzin F. RNA-mediated non-mendelian inheritance of an epigenetic change in the mouse. Nature, 2006, 441(7092): 469-474. DOI

[54] Casola S, Cattoretti G, Uyttersprot N, Koralov SB, Seagal J, Hao ZY, Waisman A, Egert A, Ghitza D, Rajewsky K. Tracking germinal center $\mathrm{B}$ cells expressing germ-line immunoglobulin $\gamma 1$ transcripts by conditional gene targeting. Proc Natl Acad Sci USA, 2006, 103(19): 7396-7401. DOI

[55] Hafner M, Wenk J, Nenci A, Pasparakis M, ScharffetterKochanek K, Smyth N, Peters T, Kess D, Holtkötter O, Shephard P, Kudlow JE, Smola H, Haase I, Schippers A, Krieg T, Müller W. Keratin 14 Cre transgenic mice authenticate keratin 14 as an oocyte-expressed protein. Genesis, 2004, 38(4): 176-181. DOI

[56] Hobeika E, Thiemann S, Storch B, Jumaa H, Nielsen PJ, Pelanda R, Reth M. Testing gene function early in the B cell lineage in mb1-cre mice. Proc Natl Acad Sci USA, 2006, 103(37): 13789-13794. DOI

[57] Wagner KU, McAllister K, Ward T, Davis B, Wiseman R, Hennighausen L. Spatial and temporal expression of the Cre gene under the control of the MMTV-LTR in different 
lines of transgenic mice. Transgenic Res, 2001, 10(6): 545-553. DOI

[58] Schmidt EE, Taylor DS, Prigge JR, Barnett S, Capecchi MR. Illegitimate Cre-dependent chromosome rearrangements in transgenic mouse spermatids. Proc Natl Acad Sci USA, 2000, 97(25): 13702-13707. DOI

[59] Thyagarajan B, Guimarães MJ, Groth AC, Calos MP. Mammalian genomes contain active recombinase recognition sites. Gene, 2000, 244(1-2): 47-54. DOI

[60] Semprini S, Troup TJ, Kotelevtseva N, King K, Davis JRE, Mullins LJ, Chapman KE, Dunbar DR, Mullins JJ. Cryptic loxP sites in mammalian genomes: genome-wide distribution and relevance for the efficiency of BAC/PAC recombineering techniques. Nucleic Acids Res, 2007, 35(5): 1402-1410. DOI

[61] Pfeifer A, Brandon EP, Kootstra N, Gage FH, Verma IM. Delivery of the Cre recombinase by a self-deleting lentiviral vector: efficient gene targeting in vivo. Proc Natl Acad Sci USA, 2001, 98(20): 11450-11455. DOI

[62] Silver DP, Livingston DM. Self-excising retroviral vectors encoding the Cre recombinase overcome Cre-mediated cellular toxicity. Mol Cell, 2001, 8(1): 233-243. DOI

[63] de Alboran IM, O'Hagan RC, Gärtner F, Malynn B, Davidson L, Rickert R, Rajewsky K, DePinho RA, Alt FW. Analysis of C-MYC function in normal cells via conditional gene-targeted mutation. Immunity, 2001, 14(1): 45-55. DOI

[64] Loonstra A, Vooijs M, Beverloo HB, Allak BA, van Drunen E, Kanaar R, Berns A, Jonkers J. Growth inhibition and DNA damage induced by Cre recombinase in mammalian cells. Proc Natl Acad Sci USA, 2001, 98(16): 9209-9214. DOI

[65] Baba Y, Nakano M, Yamada Y, Saito I, Kanegae Y. Practical range of effective dose for Cre recombinase- expressing recombinant adenovirus without cell toxicity in mammalian cells. Microbiol Immunol, 2005, 49(6): 559-570.

[66] Mähönen AJ, Airenne KJ, Lind MM, Lesch HP, Ylä-Herttuala S. Optimized self-excising Cre-expression cassette for mammalian cells. Biochem Biophys Res Commun, 2004, 320(2): 366-371. DOI

[67] Jo D, Nashabi A, Doxsee C, Lin Q, Unutmaz D, Chen J, Ruley HE. Epigenetic regulation of gene structure and function with a cell-permeable Cre recombinase. Nat Biotechnol, 2001, 19(10): 929-933. DOI

[68] Patsch C, Edenhofer F. Conditional mutagenesis by cell-permeable proteins: potential, limitations and prospects. Handb Exp Pharmacol, 2007, (178): 203-232. $\underline{\mathrm{DOI}}$

[69] Peitz M, Pfannkuche K, Rajewsky K, Edenhofer F. Ability of the hydrophobic FGF and basic TAT peptides to promote cellular uptake of recombinant Cre recombinase: a tool for efficient genetic engineering of mammalian genomes. Proc Natl Acad Sci USA, 2002, 99(7): 4489-4494. DOI

[70] Peitz M, Jäger R, Patsch C, Jäger A, Egert A, Schorle H, Edenhofer F. Enhanced purification of cell-permeant Cre and germline transmission after transduction into mouse embryonic stem cells. Genesis, 2007, 45(8): 508-517. $\underline{\mathrm{DOI}}$

[71] Patsch C, Peitz M, Otte DM, Kesseler D, Jungverdorben J, Wunderlich FT, Brüstle O, Zimmer A, Edenhofer F Engineering cell-permeant FLP recombinase for tightly controlled inducible and reversible overexpression in embryonic stem cells. Stem Cells, 2010, 28(5): 894-902. DOI

[72] Heidmann D, Lehner CF. Reduction of Cre recombinase toxicity in proliferating Drosophila cells by estrogen-dependent activity regulation. Dev Genes Evol, 2001, 211(8-9): 458-465.

[73] Seibler J, Zevnik B, Küter-Luks B, Andreas S, Kern H, Hennek T, Rode A, Heimann C, Faust N, Kauselmann G, Schoor M, Jaenisch R, Rajewsky K, Kühn R, Schwenk F. Rapid generation of inducible mouse mutants. Nucleic Acids Res, 2003, 31(4): E12. DOI

[74] Higashi AY, Ikawa T, Muramatsu M, Economides AN, Niwa A, Okuda T, Murphy AJ, Rojas J, Heike T, Nakahata T, Kawamoto H, Kita T, Yanagita M. Direct hematological toxicity and illegitimate chromosomal recombination caused by the systemic activation of CreERT2. J Immunol, 2009, 182(9): 5633-5640. DOI

[75] Jullien N, Goddard I, Selmi-Ruby S, Fina JL, Cremer H, Herman JP. Conditional transgenesis using Dimerizable Cre (DiCre). PLoS One, 2007, 2(12): E1355. DOI

[76] Lee JY, Ristow M, Lin XY, White MF, Magnuson MA, Hennighausen L. RIP-Cre revisited, evidence for impairments of pancreatic $\beta$-cell function. $J$ Biol Chem, 2006, 281(5): 2649-2653.

[77] Sato S, Fujimoto M, Hasegawa M, Takehara K, Tedder TF. Altered B lymphocyte function induces systemic autoimmunity in systemic sclerosis. Mol Immunol, 2004, 41(12): 1123-1133. DOI

[78] Kwan KM. Conditional alleles in mice: practical considerations for tissue-specific knockouts. Genesis, 2002, 32(2): 49-62. DOI

[79] Zhao L, Bakke M, Krimkevich Y, Cushman LJ, Parlow AF, Camper SA, Parker KL. Hypomorphic phenotype in mice with pituitary-specific knockout of steroidogenic factor 1 . Genesis, 2001, 30(2): 65-69. DOI

[80] Furuta Y, Behringer RR. Recent innovations in tissuespecific gene modifications in the mouse. Birth Defects Res C Embryo Today, 2005, 75(1): 43-57. DOI 
[81] Naiche LA, Papaioannou VE. Cre activity causes widespread apoptosis and lethal anemia during embryonic development. Genesis, 2007, 45(12): 768-775. DOI

[82] Ryding AD, Sharp MG, Mullins JJ. Conditional transgenic technologies. J Endocrinol, 2001, 171(1): 1-14 DOI

[83] Zhu Z, Ma B, Homer RJ, Zheng T, Elias JA. Use of the tetracycline controlled transcriptional silencer (tTS) to eliminate transgene leak in inducible overexpression transgenic mice. J Biol Chem, 2001, 276(27): 25222-25229. DOI

[84] Tong C, Li P, Wu NL, Yan YZ, Ying QL. Production of p53 gene knockout rats by homologous recombination in embryonic stem cells. Nature, 2010, 467(7312): 211-213. DOI

[85] Eisener-Dorman AF, Lawrence DA, Bolivar VJ. Cautionary insights on knockout mouse studies: the gene or not the gene? Brain Behav Immun, 2009, 23(3): 318-324.

[86] Ridgway WM, Healy B, Smink LJ, Rainbow D, Wicker LS. New tools for defining the 'genetic background' of inbred mouse strains. Nat Immunol, 2007, 8(7): 669-673. DOI

[87] Schuster-Gossler K, Lee AW, Lerner CP, Parker HJ, Dyer VW, Scott VE, Gossler A, Conover JC. Use of coisogenic host blastocysts for efficient establishment of germline chimeras with $\mathrm{C} 57 \mathrm{BL} / 6 \mathrm{~J}$ ES cell lines. Biotechniques, 2001, 31(5): 1022-1024, 1026.

[88] Ledermann B, Burki K. Establishment of a germ-line competent C57BL/6 embryonic stem cell line. Exp Cell Res, 1991, 197(2): 254-258. DOI

[89] Seong E, Saunders TL, Stewart CL, Burmeister M. To knockout in 129 or in $\mathrm{C} 57 \mathrm{BL} / 6$ : that is the question. Trends Genet, 2004, 20(2): 59-62. DOI

[90] Sharova LV, Sharov AA, Piao Y, Shaik N, Sullivan T, Stewart CL, Hogan BL, Ko MS. Global gene expression profiling reveals similarities and differences among mouse pluripotent stem cells of different origins and strains. Dev Biol, 2007, 307(2): 446-459. DOI

[91] Hansen GM, Markesich DC, Burnett MB, Zhu Q, Dionne KM, Richter LJ, Finnell RH, Sands AT, Zambrowicz BP, Abuin A. Large-scale gene trapping in C57BL/6N mouse embryonic stem cells. Genome Res, 2008, 18(10): 1670-1679. DOI

[92] Austin CP, Battey JF, Bradley A, Bucan M, Capecchi M, Collins FS, Dove WF, Duyk G, Dymecki S, Eppig JT, Grieder FB, Heintz N, Hicks G, Insel TR, Joyner A, Koller BH, Lloyd KC, Magnuson T, Moore MW, Nagy A, Pollock JD, Roses AD, Sands AT, Seed B, Skarnes WC, Snoddy J, Soriano P, Stewart DJ, Stewart F, Stillman B, Varmus H, Varticovski L, Verma IM, Vogt TF, von Melchner H, Witkowski J, Woychik RP, Wurst W, Yancopoulos GD, Young
SG, Zambrowicz B. The knockout mouse project. Nat Genet, 2004, 36(9): 921-924. DOI

[93] Mishina M, Sakimura K. Conditional gene targeting on the pure C57BL/6 genetic background. Neurosci Res, 2007, 58(2): 105-112. DOI

[94] Takeuchi T, Nomura T, Tsujita M, Suzuki M, Fuse T, Mori $\mathrm{H}$, Mishina M. Flp recombinase transgenic mice of C57BL/6 strain for conditional gene targeting. Biochem Biophy Res Comm, 2002, 293(3): 953-957. DOI

[95] Gertsenstein M, Nutter LM, Reid T, Pereira M, Stanford WL, Rossant J, Nagy A. Efficient generation of germ line transmitting chimeras from $\mathrm{C} 57 \mathrm{BL} / 6 \mathrm{~N}$ ES cells by aggregation with outbred host embryos. PLoS One, 2010, 5(6): E11260. DOI

[96] Jonkers J, Meuwissen R, van Der Gulden H, Peterse H, van der Valk M, Berns A. Synergistic tumor suppressor activity of BRCA2 and p53 in a conditional mouse model for breast cancer. Nat Genet, 2001, 29(4): 418-425. DOI

[97] Mariani FV, Ahn CP, Martin GR. Genetic evidence that FGFs have an instructive role in limb proximal-distal patterning. Nature, 2008, 453(7193): 401-405. DOI

[98] Zhang Z, Lutz B. Cre recombinase-mediated inversion using lox66 and lox71: Method to introduce conditional point mutations into the CREB-binding protein. Nucleic Acids Res, 2002, 30(17): E90. DOI

[99] Terauchi Y, Sakura H, Yasuda K, Iwamoto K, Takahashi N, Ito K, Kasai H, Suzuki H, Ueda O, Kamada N, Jishage K, Komeda K, Noda M, Kanazawa Y, Taniguchi S, Miwa I, Akanuma Y, Kodama T, Yazaki Y, Kadowaki T. Pancreatic $\beta$-cell-specific targeted disruption of glucokinase gene. Diabetes mellitus due to defective insulin secretion to glucose. J Biol Chem, 1995, 270(51): 30253-30256. DOI

[100] Norris DP, Robertson EJ. Asymmetric and node-specific nodal expression patterns are controlled by two distinct cis-acting regulatory elements. Genes Dev, 1999, 13(12): 1575-1588. DOI

[101] Urnov FD, Miller JC, Lee YL, Beausejour CM, Rock JM, Augustus S, Jamieson AC, Porteus MH, Gregory PD, Holmes MC. Highly efficient endogenous human gene correction using designed zinc-finger nucleases. Nature, 2005, 435(7042): 646-651. DOI

[102] Urnov FD, Rebar EJ, Holmes MC, Zhang HS, Gregory PD. Genome editing with engineered zinc finger nucleases. Nat Rev Genet, 2010, 11(9): 636-646.

[103] Anastassiadis K, Fu J, Patsch C, Hu SB, Weidlich S, Duerschke K, Buchholz F, Edenhofer F, Stewart AF. Dre recombinase, like Cre, is a highly efficient site-specific recombinase in E. coli, mammalian cells and mice. Dis Model Mech, 2009, 2(9-10): 508-515. 
